\title{
"ESTRATIGRAFIA" DE ROCHAS GRANITÓIDES NA REGIÃO DO SERIDÓ (RN-PB) COM BASE EM CRITÉRIOS ESTRUTURAIS
}

\author{
EMANUEL FERRAZ JARDIM DE SÁ*, JEAN.MICHEL LEGRAND*E IAN McREATH*
}

\begin{abstract}
The granitoid rocks of the Serido region, Northeast of Brazil, have been ascribed to a chronologic sequence based in their structural features and other field criteria.

The supracrustal sequence is intruded by three major granitoid generations $\left(G_{2}, G_{3}, G_{4}\right)$, ranging from pre-to post-tectonic with respect to one of two main folding phases $\left(\mathrm{F}_{2}, \mathrm{~F}_{3}\right)$. The older types $\left(\mathrm{G}_{2}\right)$ are extensively gneissified and were interpreted as basement in previous geological synthesis. The younger ones $\left(G_{3}, G_{4}\right)$ appear in large diapiric complexes or minor intrusions.

In basement nuclei it is possible to distinguish even older orthogneisses $\left(G_{1}\right)$, sometimes comprising a large volume of the terrain, intruding amphibolites and other country rocks.

Aspects of the relationships between the granitoid events and the tectonic evolution of the region are further discussed.
\end{abstract}

INTRODUÇÃO Os trabalhos prévios sobre granitos do nordeste (em especial Almeida et. al., 1967; Ebert, 1969; Ferreira e Albuquerque, 1969; Santos, 1969 e 1973; e Brito Neves e Pessoa, 1974) em geral tentam uma sintese de conhecimentos sobre uma área muito extensa e ainda pobremente conhecida, especialmente se considerarmos sua complexidade. Existe igualmente uma ênfase no estudo das rochas graníticas mais jovens, pouco deformadas, referidas ao Ciclo Brasiliano (Cordani, 1974; Brito Neves et al., 1974; Brito Neves, 1975 etc.).

Comparado a algumas das sínteses prévias, este trabalho envolve uma restrição em área (a região do Seridó) e uma extensão no tempo para incluir os granitóides mais antigos. Nosso objetivo é discutir as bases para uma estratigrafia de granitos na região relacionados cronologicamente entre si $\mathrm{e}$ às fases de deformação e metamorfismo reconhecidas (Jardim de Sá, 1978). Acreditamos que tal esquema será de grande utilidade para orientar subseqüentes investigaçðes geocronológicas na região. Além das relaçōes clássicas de intrusão/inclusão, lançamos mão de critérios estruturais para confrontar os diferentes corpos entre si e com suas encaixantes. Uma nota preliminar já foi emitida sobre o assunto (Jardim de Sá et al., 1978).

A evolução geológica regional envolve um mínimo de três eventos tectonometamórficos importantes. $O$ mais antigo $\left(F_{1} / M_{1}\right)$ é comprovado pelo caráter transposto do bandeamento gnáissico nos núcleos interpretados como embasamento, obliterando outras estruturas mais antigas, além de padróes de redobramento $F_{2} / F_{1}$ variáveis e foliaçð̃es/lineação afetadas por $F_{2}$. Estruturas recumbentes $\left(F_{2}\right)$ e formação de augen gnaisses $\left(M_{2}\right)$ na base de supracrustais são característicos do segundo evento enquanto o terceiro envolve dobramentos abertos e fechados com plano axial de mergulho forte $\left(F_{3}\right) \mathrm{e}$ metamorfismo acompanhante $\left(M_{3}\right) . F_{2}$ e $F_{3}$ têm orientaçð̃es próximas entre si de NE a NNE. Clivagem de fra- tura e crenulação, e zonas de cisalhamento subverticais, longitudinais ou transversais, aparecem localmente e podem constituir um evento $F_{4}$, acompanhado ou não de retrometamorfismo $\left(M_{4}\right)$. A Fig. 1 esquematiza a geologia da região e indica as localidades citadas no texto.

Os índices numéricos a seguir utilizados na notação dos granitóides referem-se a associações consideradas relacionadas às fases tectônicas distinguidas enquanto as letras designam subtipos e/ou seqüências dentro das associações.

\section{AS ROCHAS GRANITÓIDES NO EMBASAMEN-}

TO A associação $G_{1}$ é a mais problemática a definir, inclusive pela própria dificuldade em caracterizar as áreas de embasamento. Alguns candidatos provêm da região de Caicó e leste de Serra Negra do Norte (RN), na forma de grandes xenólitos de ortognaisses finos e médios, equigranulares, inclusos em augen gnaisses. A composiçâo é granodiorítica a tonalítica, diorítica mais raramente. Os máficos são biotita e hornblenda. Por sua vez, esses gnaisses contêm xenólitos de anfibolitos (Fig. 2a).

A leste de $A c ̧ u(R N)$ ocorrem biotita gnaisses de composição granodiorítica a tonalítica, com ou sem hornblenda, cor cinza, granoblásticos. Os mesmos estão intercalados/interfoliados com anfibólitos do embasamento e, em alguns pontos, o gnaisse exibe relaçð̃es intrusivas com o anfibólito. Possuem um bandeamento e fábrica de biotita, redobrados no evento $F_{2}$ (Fig. $2 b$ ). São também encontrados augen gnaisses de composição nos quais domina granodiorítica cinza ou rósea. Localmente, é possível constatar a existência de uma seqüência de fases, as mais antigas de composição dioritica, incluídas como xenólitos e intrudidas por tipos mais potássicos, róseos. Todos eles são afetados pelas estruturas $F_{1}$. 

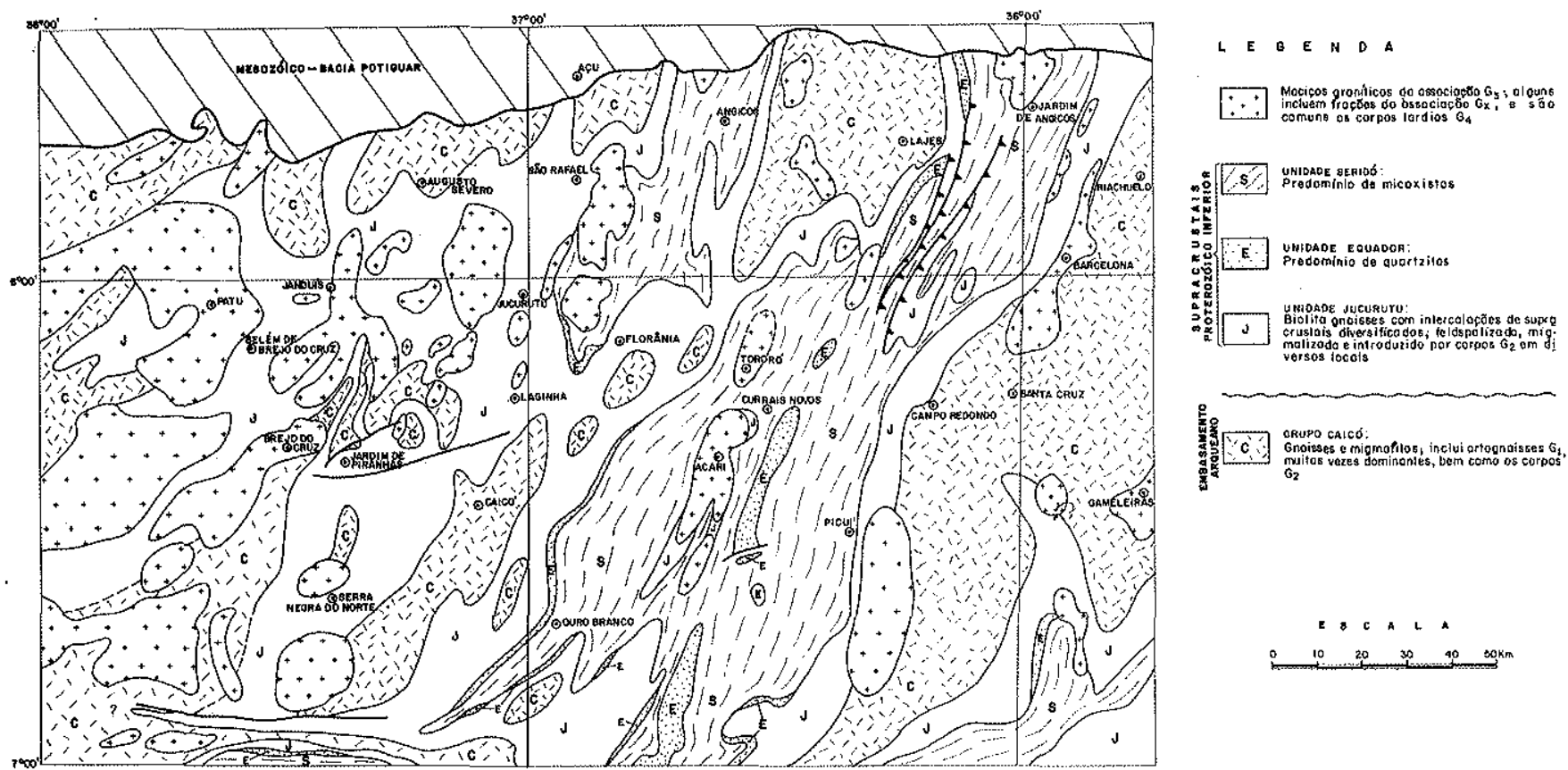

Figura 1 - Geologia esquemática e localização de alguns corpos graníticos na região do Seridó (RN-PB) (Adaptado de Jardim de Sá e Salim, 1980)

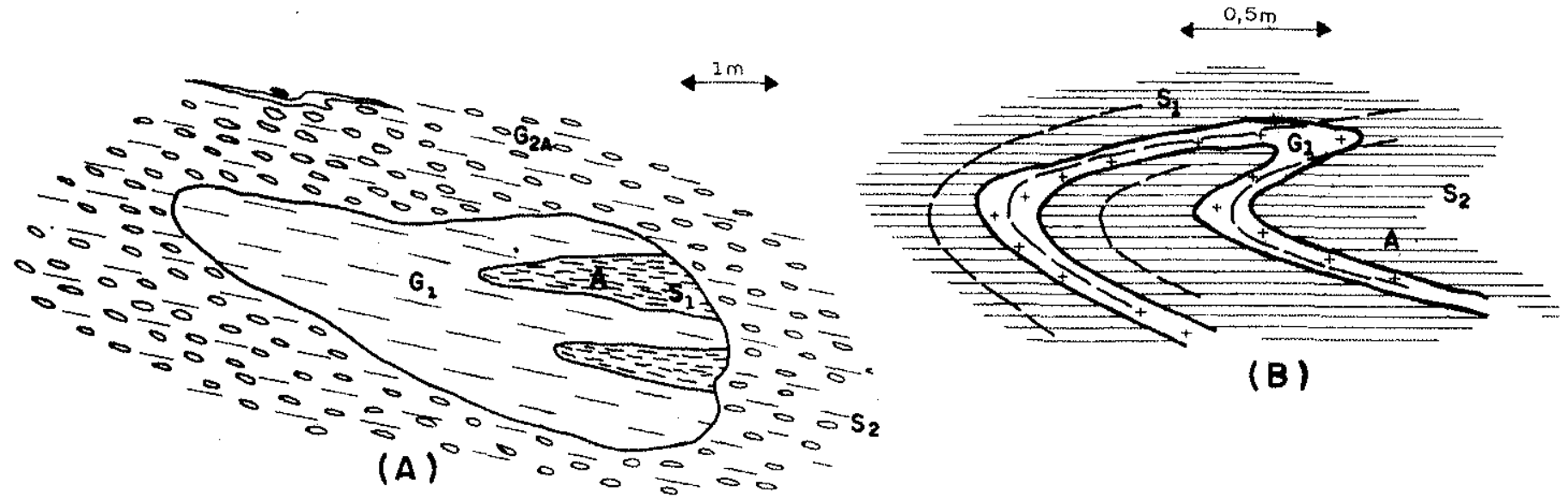

Figura 2 - (A) Augen gnaisse $\left(G_{2 A}\right)$ contendo xenólitos de um granodiorito $\left(G_{1}\right)$, o qual por sua vez contém xenólitos de anfibólito (A). A foliação do augen gnaisse é correlata ao evento $F_{2}$. Baseado em afloramento a NE de Serra Negra do Norte. (B) Sheet gnáissico $\left(G_{1}\right)$ aparentemente intrusivo em anfibólito (A) do embasamento, mostrando interferência $F_{2} / F_{1}$. Afloramento a leste de Açú.

Mencionamos ainda algumas rochas migmatizadas nas regiôes a leste de Açu e ao sul de Augusto Severo (RN). No primeiro caso, trata-se de um migmatito nebulítico-porfiroblástico, milonítico, com hornblenda, incluindo anfibólitos e gnaisses. Ao sul de Augusto Severo, trata-se de um migmatito bandado e nebulítico, com redobramentos complexos.

Seixos graníticos, equigranulares e porfíríticos ocorrem no metaconglomerado Ouro Branco (RN) e em outros metaconglomerados da região, apoiando adicionalmente a existência deste grupo.
AS ROCHAS GRANITÓIDES ASSOCIADAS A $F_{2} \quad$ Compreendem volumosa representação que pode ser agrupada em dois subtipos.

O mais importante volumetricamente $\left(G_{2 A}\right)$ reúne augen gnaisses e ortognaisses porfiroblásticos, formados por feldspatização e anatexia $\left(M_{2}\right)$ pré a sintectônica $\left(F_{2}\right)$ de rochas do embasamento e niveis inferiores das supracrustais. A feldspatização referida envolve a "quebra" das micas em reaçðes produzindo K-feldspato, magnetita ou sillimanita, e liberando $\mathrm{H}_{2} \mathrm{O}$. A migração dos fluidos numa escala de no máximo alguns metros 
configura um processo de porfiroblastese, ou metassomatismo de pequena escala. Com o contínuo aumento de temperatura, auxiliado pela presença de fluidos, a isógrada da anatexia é atingida. A composição do material formado varia de granito-granodiorito com biotita, e hornblenda subordinada (o protomaterial seria principalmente os gnaisses biotíticos, supracrustais), a granodioritos e tonalitos com predomínio do anfibólio sobre a mica (protomaterial do embasamento gnaisseanfibolítico). Mobilizados de quartzo-plagioclásiohornblenda atestam a alta temperatura que o evento $M_{2}$ atingiu em alguns setores. As texturas augen são as mais desenvolvidas, às vezes substituídas pela porfiroblástica (agregados de quartzo mais plagioclásio mais ou menos hornblenda) nos tonalitos.

A foliação mais marcada nessas rochas é um bandeamento gnáissico junto com a orientação dos augen e porfiroblastos de hornblenda. Uma lineação de estrias e barras é também marcante. Em parte parece refletir a interseção de dois planos subparalelos, um dos quais é uma foliação milonítica, com quartzo estirado (quartz ribbon), mais antiga, e a outra é a foliação de plano axial, micácea, de $F_{2}\left(S_{2}\right)$. Alguns veios quartzofeldspáticos estão dobrados em estilo intrafolial em relação a $S_{2}$ (Fig. 3a). Uma segunda deformação afeta o bandeamento, sendo a respectiva foliação de plano axial $\left(S_{3}\right)$ denunciada por uma fábrica de biotita (muscovita mais raramente) menos proeminente (Fig. $3 b$ ). Veios graníticos a aplíticos mais novos que a fábrica $F_{2}$ e afetados por $F_{3}$ indicam remobilização da rocha provavelmente nesse evento mais jovem $\left(M_{3}\right)$. Zonas de cisalhamento combinadas a mobilizaçōes graniticas difusas constituem o último evento detectado $\left(F_{4} / M_{4}\right.$ ?) formando estruturas dictioníticas.

Os xenólitos e restitos presentes são muitas vezes de natureza similar à dos encaixantes do augen gnaisse, sugerindo que o posicionamento não envolve deslocamentos importantes nesses casos. Podemos relacionar como xenólitos mais comuns os de anfibólitos, metagabros e gnaisses com biotita/hornblenda nos granitóides no embasamento, e biotita gnaisses e xistos (inclusive da uni- dade Jucurutu), biotita anfibólitos, gnaisses quartzofeldspáticos, quartzitos, calcossilicáticas etc., quando os augen gnaisses cortam as supracrustais. Estruturas migmatíticas são mais freqüentes no caso do embasamento, sendo a anatexia nas supracrustais mais avançada (rochas quimicamente mais favoráveis?).

Esses granitoides formam corpos de variadas dimensões. Em Lages (RN), temos larguras de afloramento da ordem de 3 a $4 \mathrm{~km}$ transversalmente à direção regional NNE, com formas interdigitadas pelo dobramento $F_{2}$. Os contatos variam de gradacionais (aumento de feldspatização e anatexia) a intrusivos e tectônicos, concordantes com a foliação $S_{2}$ ou ligeiramente discordantes com o bandeamento gnáissico $S_{1}$. Na região a oeste de Angicos (RN), ocorrem augen gnaisses em contato com supracrustais (xistos e metarcósios) cujo primeiro metamorfismo $\left(M_{2}\right.$; também $\left.M_{3}\right)$ não atingiu grau elevado. Os estudos em andamento ainda não constataram efeitos de contato nem uma elevação anormal no gradiente metamórfico da região. Fenômenos de feldspatização progressiva são mais bem observados em níveis supracrustais em fácies anfibólito. Uma mobilização tardia de augen pegmatitos (cortam as dobras $F_{2}$ mas ainda possuem a foliação $S_{2}$ ) pode ser importante localmente.

Bons exemplos de granitóides $G_{2 A}$ podem ser observados na base das supracrustais por toda a região (leste de Caicó, Serra do Feiticeiro etc.) ou em áreas de embasamento (Lages, leste de Açu etc.).

O segundo subtipo de granitóides $\left(G_{2 B}\right)$ não envolve a feldspatização observada no caso anterior, parecendo formado diretamente por anatexia de material do embasamento ou da seqüência metassedimentar. A composição é mais ácida, geralmente granítica a granodiorítica, com biotita e hornblenda. Textura granoblástica é generalizada bem como faixas de quartzo estirado, estas últimas especialmente desenvolvidas na região de contato embasamento-cobertura, como efeito milonítico. Esses tipos variam de migmatitos bandados, nebulíticos e schlieren a ortognaisses mais homogêneos. Mais uma vez as foliações presentes são subparalelas entre si e ao

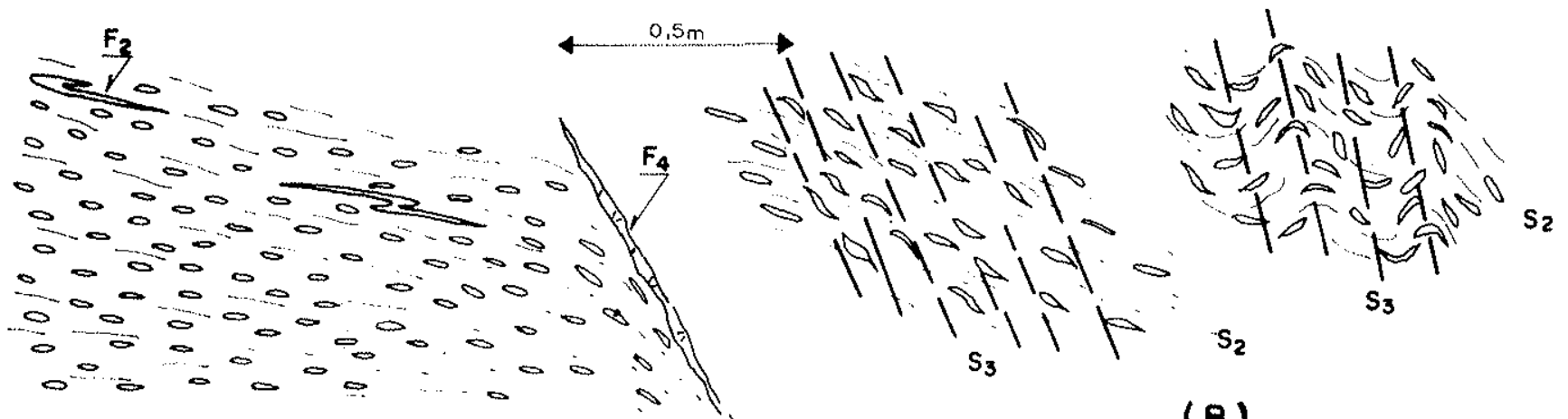

(A)

Figura 3 - (A) Augen gnaisse com foliaçào correlata à deformação mais antiga nas supracrustais $\left(S_{2} / F_{2}\right)$, com dobras intrafoliais $\left(F_{2}\right)$ em veios quartzo-feldspáticos. Os augen podem ser bem desenvolvidos ou estar fortemente estirados produzindo um bandeamento mais regular (parte inferior do desenho). Em $F_{4}$ temos uma zona de cisalhamento tardia. Baseado em afloramentos próximos a Lages. (B) Clivagem de crenulação e minidobras correlatas a $F_{3}$, afetando a foliação de $F_{2}$. Baseado em afloramentos na Serra do Feiticeiro e leste de Serra Negra do Norte 
plano axial de $F_{2}$, caracterizando a migmatização/intrusão como cedo à sintectônica. Mobilizados e veios pegmatíticos podem mostrar dobramentos isoclinal $e$ padrões de interferência. As foliaçōes milonitica e de biotita podem estar dobradas em escala de afloramento, por efeito de $F_{3}$, ou aparecer uma outra foliaçâo mais jovem desta última deformação. Um último evento envolve mobilizações graníticas difusas em zonas de cisalhamento, tal como em $G_{21}$.

Esse tipo também possui variados xenólitos, anotando-se novamente o material encaixante - biotita gnaisses e xistos, anfibólitos e os augen gnaisses/gnaisses granitizados $G_{2 A}$, indicando a relação cronológica entre ambos (diques $G_{2 B}$ cortando o augen gnaisses $G_{2 A}$ também são comuns e novamente confirmam a relação). Estruturas schollen e schlieren podem estar presentes.

Os jazimentos variam de autóctones ou pouco deslocados nos corpos maiores, migmatíticos (diques e sheets com 1-2 km de comprimento e algumas dezenas de metros de espessura), a diques menores e outros corpos caracteristicamente intrusivos. Neste último caso, a diferenciação de outros tipos pode ser problemática pois os diques tendem a ser tardios e a ter as estruturas antigas pouco desenvolvidas e facilmente obliteradas por remobilização posterior.

\section{ROCHAS GRANITÓIDES DE POSICIONAMENTO INTERMEDIÁRIO-DUVIDOSOS No Maciço de} Acari (RN), ao sul da Serra Negra do Norte e em diversos outros locais, ocorre uma associação plutônica de posicionamento e caráter ainda duvidosos. Os granitos porfiríticos do maciço (ver adiante) constituem uma seqüência complexa de intrusões, desde pré ou cedo, sin e tardi- $F_{3}$. Tais granitos incluem xenólitos ou cortam corpos de dioritos, tonalitos e granodioritos, de textura eqüigranoblástica, gnáissicos e localmente schlieren. Uma das fases típicas é uma rocha diorítica a quartzogabróide, com "pontuações" de hornblenda alinhada por fluxo e/ou tectonismo, e que também ocorre em diques inclusive cortando discordantemente $o$ bandeamento do augen gnaisse $G_{2 A} \mathrm{e}$, assim, definindo sua cronologia.

A interpretação é duvidosa mas pode haver uma seqüência de diferenciação de gabros e dioritos a tonalitos e granadioritos. A hornblenda pode ser o ferromagnesiano dominante. Os tipos mais ácidos exibem foliação mais conspícua (biotita metamórfica) e incluem progressivamente rochas mais básicas em estruturas agmatíticas. Xenólitos supracrustais parecem menos abundantes e incluem anfibólito, xisto e gnaisse, além de rochas graniticas $\left(G_{2 B}\right.$ ?).

Esses granitóides formam corpos de contatos bem definidos, claramente intrusivos. O problema do metamorfismo de contato não pôde ser investigado devido aos eventos superpostos e à inclusão em corpos mais jovens. Seu posicionamento é duvidoso - corpos atectônicos, pré- $F_{3}$ e pós- $F_{2}$, ou sintectônicos em relação a um evento de menor importância ainda não caracterizado convenientemente nas supracrustais. Podem ser representados pela notação $G_{x}$.

\section{AS ROCHAS GRANITÓIDES ASSOCIADAS A}

$F_{3} \quad$ Esta é a associação mais conspícua e volumetricamente só aproximada pelos granitóides $G_{2 A}$. São observados três subtipos principais e evoluções migmatíticas, paralelos e/ou defasados no posicionamento quanto a $F_{3}$. Clivagem de fratura e crenulação, subparalelas a $S_{3}$, podem ter sido seguidas por zonas de cisalhamento subverticais e dobras transversais, com retrometamorfismo em fácies xisto verde, definindo uma fase $F_{4} / M_{4}$ dificilmente separável de um "pulso" final de $F_{3} / M_{3}$.

Numa seqüência complexa de intrusões, mas mais antigas $\left(G_{3 A}\right)$ correspondem a granitos porfiríticos "dente de cavalo", com hornblenda e biotita. Podem estar foliados nas bordas, efeito superposto à orientação dos fenocristais por fluxo do magma. São característicos os cristais zonados de microclina com inclusões de biotita paralelas às faces e orlados por plagioclásio (textura rapakivi). Mais raramente, temos cumulados de $\mathrm{K}$-feldspato e bandeamento rítmico (alternância feldspatos versus máficos). A foliação e a estrutura de fluxo podem ser afetadas por dobras com planos axial subvertical, características da fase $F_{3}$ (Fig. 4). Os xenólitos incluem as supracrustais, básicas e ultrabásicas, e rochas da associação $G_{X}$. Os corpos são do tipo mesodiapírico, estão por sua vez inclusos em rochas sintectônicas, inferindo-se daí seu posicionamento pré e cedo-tectônico em relação a $F_{3}$. Exemplos inciuem o "granito de Acari" (parte do batólito, Fig. 5) e.porçóes dos corpos de Monte das Gameleiras, Patu e Barcelona (RN).

O granito porfirítico $G_{3 A}$ em Patu está incluso em um granitóide cinza e róseo, eqüigranular, com fácies nebulítica e schlieren - o tipo $G_{3 B}$. Essas estruturas são irregulares, sem controle pela foliação de plano axial de $F_{3}$, assemelhando-se a um bandeamento ígneo em rocha altamente mobilizada. A biotita orienta-se no plano $S_{3}$ o que localmente também é observado com quartzo estirado. Xenólitos presentes incluem biotita xistos e gnaisses, biotita anfibólitos e dioritos com hornblenda $\left(G_{X}\right)$. Sua variável assimilação pelo granitóide pode ser responsável, ao menos em parte, pelo bandeamento difuso e estruturas schlieren. Os exemplos em Patu e ao norte do Maciço de Acari parecem formar stocks, bolsðes e pequenos corpos. A leste de Açu são observados diques de composição granítica mostrando bandeamento similar, neste caso tipicamente de fluxo, paralelizando as paredes de diques e apófises. Próximo a Angicos ocorrem stocks desse granito, inclusive com dobras $F_{3}$ afetando o bandeamento de fluxo.

Talvez $z_{+}$correlato, no tempo, à mobilização de $G_{3 B}$, temos a formação de migmatitos bandadoporfirobláticos observados na região de Barcelona. $O$ paleossoma é um gnaisse migmatítico mais antigo interpretado como embasamento. O neossoma é granítico com porfiroblastos de $\mathrm{K}$-feldspato preservados ou deformados por um evento que corresponde a $F_{3}$. Esse tipo de migmatito parece ter resultado da intrusão dos mesodiápiros $G_{3 A}$, aquecendo as encaixantes e provocando sua anatexia. Os maciços de Acari e Barcelona parecem assim constituídos por uma orla de granitos mais jovens (Fig. 5), provavelmente evoluidos da anatexia da parte basal das supracrustais, bem como do em- 

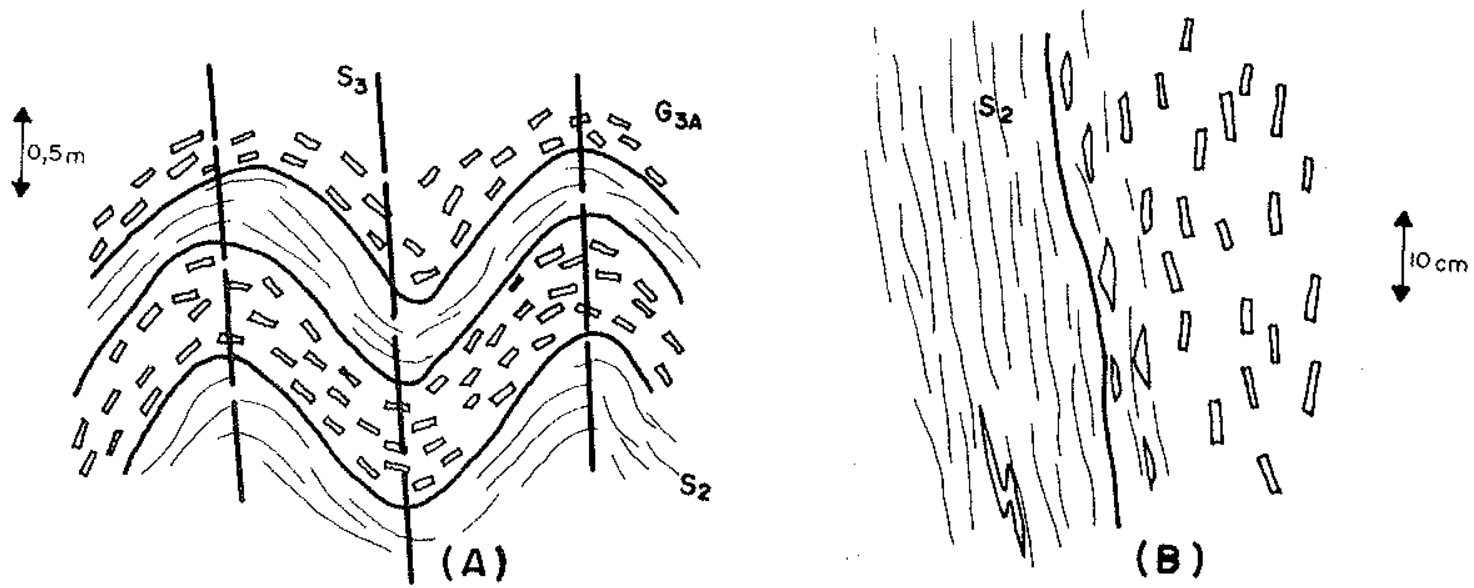

Figura 4 - (A) Filões de granito porfïrítico $G_{3 A}$, com estrutura de fluxo ressaltada pelos feldspatos, paralela às paredes de filão. A intrusão é concordante com a primeira foliação nos micaxistos encaixantes $\left(S_{2} / F_{2}\right)$, sendo dobrada com plano axial subvertical em $F_{3}$. Baseado em afloramento a SE de Acari. (B) Detalhe em um contato micaxisto/granito porfirítico $G_{3 A}$. Os feldspatos estão orientados por fluxo, e estirados próximo à borda do granito. Baseado em afloramento ao norte de Acari.

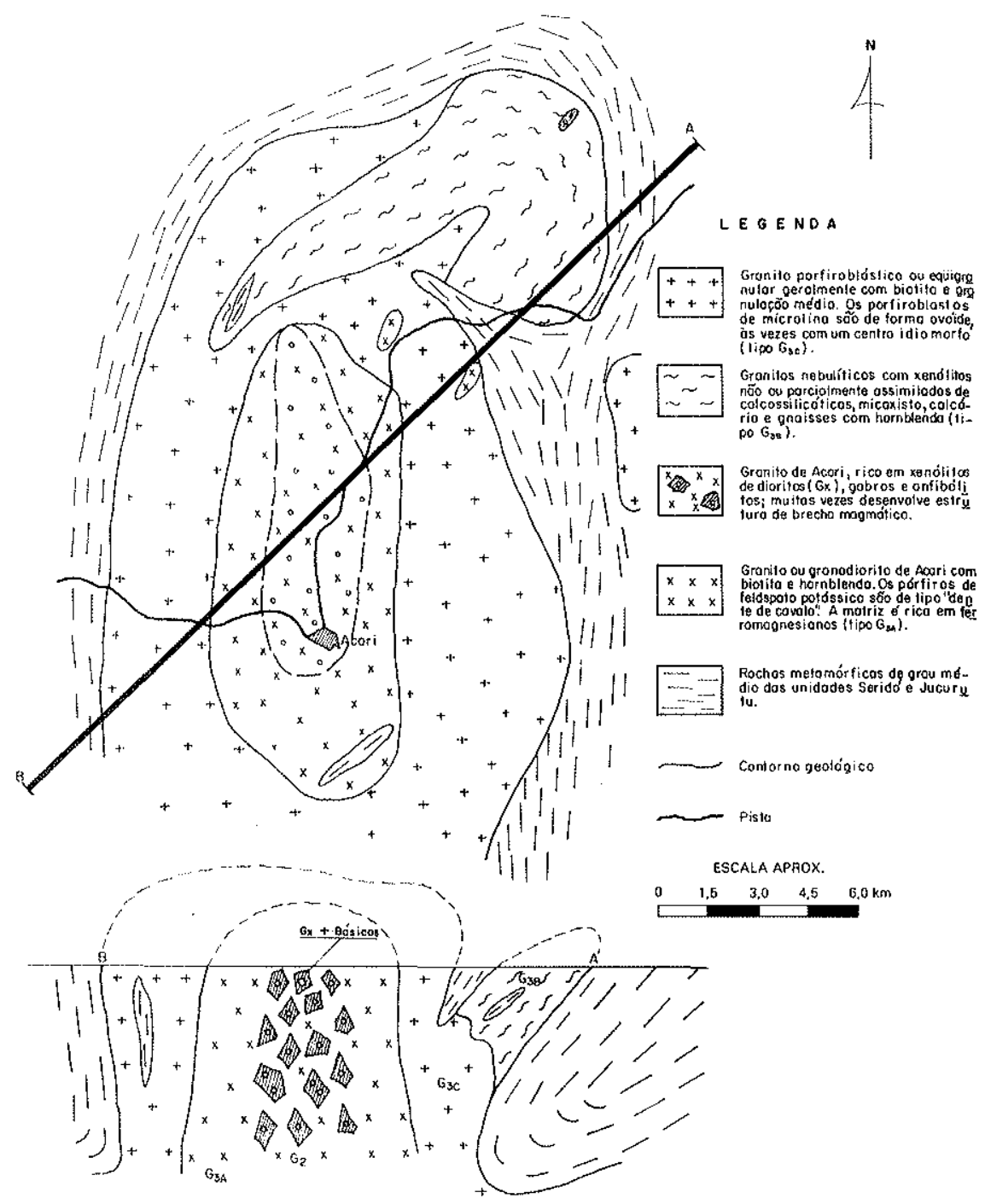

Figura 5 - Estrutura polidiapirica do maciço de Acari, RN 
basamento, aquecidas pelos diápiros; o migmatito antes referido pode representar um estádio inicial do processo, preservado. As partes mais externas dos maciços são formadas por granitos e granodioritos porfiroblásticos ou eqüigranulares $\left(G_{3 c}\right)$, de granulometria média e aparentando menor densidade de fenocristais. As fácies de borda são bem foliadas. A matriz também é mais fina. Os xenólitos incluem o granito "dente de cavalo", rochas básicas, biotita xistos e gnaisses, e rochas da associação $G_{X}$. Outros exemplos ocorrem em Lages, Montes das Gameleiras, Brejo do Cruz (PB) etc. Este tipo de granito deve corresponder a intrusões $\sin$ a tardi- $F_{3}$.

$\mathrm{O}$ acúmulo de um maior volume de líquido anatético, talvez a partir dos granitos nebulíticos $G_{3 B}$, permitiu a formação de diques e stocks de granito e granodiorito cinza e róseo, equiigranular, fino a médio, pouco ou não deformado $\left(G_{4}\right)$. As intrusōes devem ser tardi a pós- $F_{3} / F_{4}$ (Fig. 6), e podem mostrar estruturas de fluxo com xenólitos alinhados. Estes incluem supracrustais, granitos porfirítico-porfiroblásticos e da associação $G_{X^{*}}$. Diques menores também ocorrem, simples ou compostos, às vezes desenvolvendo brechas magmáticas. Bons exemplos ocorrem em Brejo do Cruz (PB), Acari, São Rafael, Dona Inês (PB) etc. Estão freqüentemente associados a stockworks de aplitos, por sua vez cortados por pegmatitos e veios de quartzo, todos pós-tectônicos.

DISCUSSÃo A estratigrafia de granitos aqui proposta e resumida na $\mathrm{Tab} . \mathrm{l}$ admite que os eventos tectônicos são penetrativos regionalmente de acordo com a coincidência dos resultados de estudos estruturais em diferentes áreas. O esquema representa uma hipótese preliminar e necessita de um confronto e aprimoramento com estudos de maior detalhe em diversas regiðes, bem como com datações radiométricas. Dados geoquímicos são igualmente necessários para estabelecer melhor as relaçōes entre algumas associaçð̃es $-G_{X}$ versus $G_{3}, G_{2 A}$ versus $G_{2 B}$ etc.

Os granitóides de embasamento são os mais difíceis de caracterizar devido a sua extensiva gnaissificação e interfoliação com outros litotipos. Relações intrusivas devem ser cuidadosamente procuradas para estabelecer a origem dos gnaisses. Sua idade pode remontar ao Arqueano com base na datação de Brito Neves et. al. (1975) e Pessoa (1976) para o Grupo Caicó em sua áreatipo $-t=2760 \pm 100$ m.a. e $R_{\mathrm{o}}=0,701 \pm 0,0014$ (valor de $t$ recalculado para $i=1,42 \times 10^{-11}$ anos $^{-1}$, inclusive nas citações que se seguem).

Os granitóides associados ao primeiro evento de deformação das supracrustais $\left(F_{2}\right)$ variam de tipos autóctones, feldspatizados, a augen gnaisses mobilizados, geralmente em corpos estratóides (sheets). Suas formas e estruturas revelam forte controle pela tectônica de dobras com plano axial suave, recumbentes e tipo nappe. Diques e outras formas intrusivas, discordantes, tornam-se mais importantes em etapa tardia daquele evento.

Tabela 1 - Sumário das características dos granitóides da região do Seridó (RN-PB)

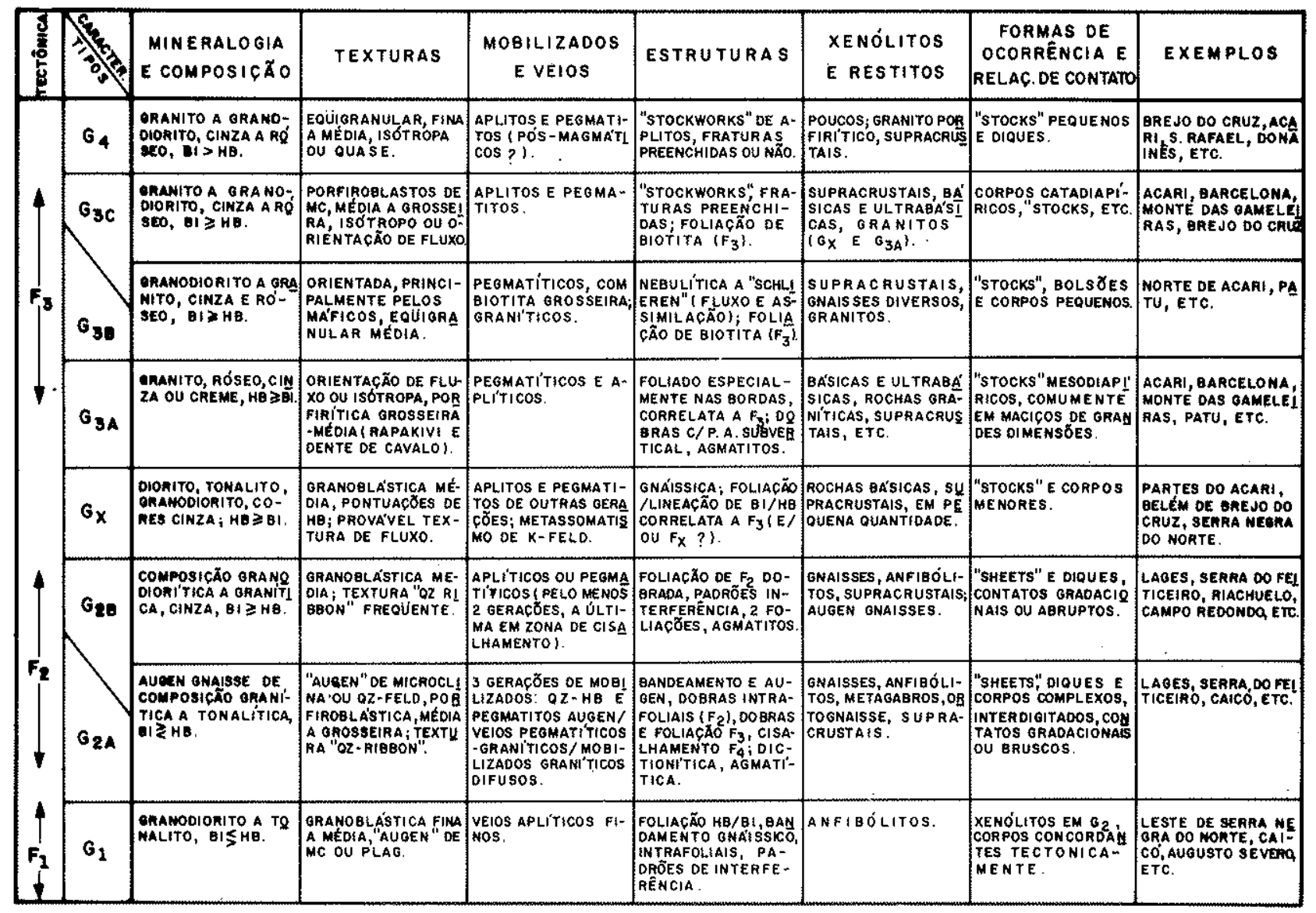




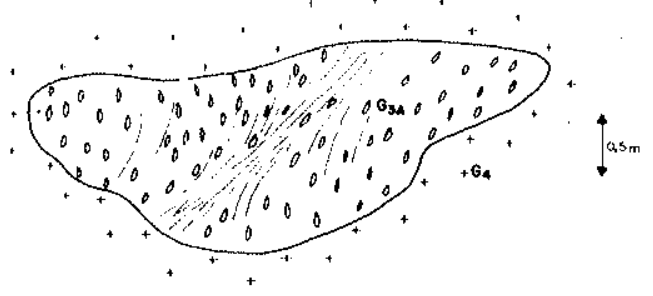

Figura 6 - Granito porfititico $\left(G_{3,1}\right)$ deformado por zona de cisalhamento $\left(F_{4}\right.$ ?) e incluso como xenólito em granito eqüigranular isótropo $\left(G_{4}\right)$. Bascado em afloramento a oeste de Jardim de Piranhas.

McReath e Jardim de Sá (1979), discutindo dataçðes publicadas e inéditas, deixam aberta a possibilidade de que a idade desses granitos se situem entre 1,1 e 2,2 b.a. Este último valor parece-nos o mais provável. Pessoa (1976) datou ortognaisse ao sul de Florânia, numa área dominada pela unidade "basal" das supracrustais (Jucurutu) e granitóides $G_{2}$. Foi obtida uma isócrona combinada de dois afloramento com $t=2250 \pm 40 \mathrm{~m}$.a. e $R_{\mathrm{o}}=0,7021 \pm 0,0004$. O baixo valor de $R_{0}$, em comparação à isócrona de Caicó, indica que as rochas ao sul de Florânia não constituem o retrabalhamento dos mesmos gnaisses do embasamento e assim devem representar material neoformado naquele evento.

Os granitóides $G_{1}$ e $G_{2}$ não encontram paralelo em classificações prévias de tipos de granitos da região, tais como estabelecidas por Almeida et al. (1967) e Santos e Melo (1978). Sua extensiva gnaissificação impede a aplicação do termo "granito" aos mesmos, no sentido petrográfico. Em trabalhos prévios de mapeamento, essas rochas foram consideradas como embasamento dos metassedimentos, o que não se verifica no caso dos tipos $G_{2}$.

Uma das características peculiares dos granitóides mais jovens $\left(G_{3}\right.$, principalmente) é sua intima associação com rochas básicas, incluídas como xenólitos ou constituindo pequenos stocks e massas de gabros e dioritos. Dataçס̃es K/Ar de alguma dessas rochas situam-se no intervalo 700-1 470 m.a. o que pode ser tomado como uma primeira estimativa para a idade da associação $G_{X}$, com a qual estão frequientemente associados. As mesmas correspondem ao que Santos e Melo (1978) descreveram como a parte máfica da "associação diorito-granito pórfiro". Mello (1972) interpretou-as como remanescentes da constituição original dos maciços a partir das quais a composição granítica seria alcançada por generalizado metassomatismo potássico.

As rochas básicas possuem alguns diferenciados ricos em plagioclásio e fraçð̃es ultrabásicas (hornblendapiroxênio). Nos gabros, podem-se encontrar hiperstênio e augita. Xenólitos de rochas do fácies granulito (charnockitos, cordierita-hiperstênio gnaisses) são também encontrados mais raramente nos granitos, às vezes próximos aos gabros. Essas intrusðes básicas posicionam-se do nível do embasamento aos micaxistos mais superiores.

Os granitos mais jovens desenvolvem-se sob formas diapíricas em grandes batólitos compostos (Santos, 1973; e Legrand, 1977). Neste caso, as intrusðes cortam ou incluem rochas granitóides precedentes (Fig. 5), num processo de polidiapirismo (Stephansson, 1975). Uma análise dos mapas geológicos da província deixa entrever certa regularidade no comprimento de onda medido entre os eixos desses batólitos, perpendicularmente ao trend NNE regional (por exemplo, Monte das Gameleiras-Picuí/Barcelona-Acari/oeste de LagesJucurutu/São Rafael etc.), da ordem de $50 \mathrm{~km}$. A partir de Jucurutu (RN) para oeste, o espaçamento diminui e as dimensões e número de diápiros parecem aumentar (ver a carta geológica ao milionésimo; Dantas, 1974). Em corpos menores foram recentemente descritas estruturas circulares (McReath e Perrin, 1979).

Os granitos $G_{3 A}$ correspondem à maior parte dos corpos tipo Itaporanga, da classificação de Almeida $e t$ al. (op. cit.) enquanto o $G_{3 B}$ equivaleria ao tipo Conceição. Os granitos $G_{3 C}$ poderiam ser identificados com um ou outro tipo, o que mostra a necessidade de aperfeiçoamento daquela classificação. Por outro lado, o esquema de Santos e Melo (op. cit.) para os granitos sinorogênicos incorpora um outro elemento, que é o nível estrutural de posicionamento dos corpos. Assim, sua "associação diorito-granito porfiróide" seria mais antiga e de maior profundidade. $O$ "granito porfiróide" deve corresponder em sua maior parte ao nosso tipo $G_{3 A}$. A segunda associação, "tonalito-granito", seria mais jovem, móvel e de menor profundidade. Esta equivale a nossos tipos $G_{3 B}$ e $G_{3 C}$, ainda que alguns desses últimos possam ser comparados aos "granitos porfiróides" antes citados, um problema idêntico ao da classificação de Almeida $e t$ al. (op. cit.). A noção de profundidade da intrusão também nos parece enfrentar problemas em alguns corpos; o granito porfirítico de Acari, por exemplo, tipo $G_{3 A}$, correlato à associação "diorito-granito porfiróide", tem feiçðes de intrusão de alto nivel - brechas magmáticas (xenólitos básicos angulosos), deformação milonítica nos contatos, que são bruscos etc. Finalmente, adicionamos aqui os granitos $G_{4}$, que seriam equivalentes ao tipo Itapetim, de Almeida et al. (op. cit.). Nesșe tipo, todavia, têm sido classificados corpos mais antigos das categorias $G_{3 B}$ e $G_{3 C}$. Este fato já havia sido notado por Santos e Melo (op. cit.) que interpretaram os filoes Itapetim, intrusivos nos corpos da associação diorito-granito porfiróide, como equivalentes de profundidade da associação tonalito-granito; não concordamos com essa generalização, todavia.

O episódio de deformação $F_{3}$ é atribuído ao Ciclo Brasiliano, cerca de $650 \pm 30$ m.a., com base em datações dos corpos graníticos mais jovens (Brito Neves, 1975 e dados inéditos), correspondentes ao tipo $G_{3}$. As características desse episódio incluem dobras com plano axial vertical ou subvertical, de vergência variável, me- 
tamorfismo regional de pressões baixas (com andaluzita e cordierita) e o volumoso plutonismo granítico. Datações dos tipos $G_{3}$ e $G_{4}$ na região são ainda deficientes. Brito Neves et al. (1974) lançaram em diagrama isocrônico amostras de maciços e corpos graníticos que devem corresponder aos mesmos, embora provenientes de três setores distintos da província brasiliana nordestina. Duas linhas de referência tentativas foram traçadas. Uma delas, $\operatorname{com} t=650 \pm 10 \mathrm{~m}$.a., inclui três amostras do Seridó enquanto duas outras amostras situam-se numa reta com $t=560 \pm 23 \mathrm{~m}$.a. Não é possível, todavia, classificarmos as amostras em nosso ou em outro sistema. Como sugestão, pode-se tentativamente correlacionar os tipos $G_{3}$ à isócrona de 650 m.a., o que está em acordo com isócronas confiáveis de rochas similares em outras regiões do nordeste (Brito Neves, 1975 e dados inéditos); o tipo $G_{4}$ corresponderia à idade menor, de $560 \mathrm{~m}$.a. Os dados $\mathrm{K} / \mathrm{Ar}$ em rochas graníticas existentes são de interpretação ainda mais problemática, variando de 710 a 454 m.a. (Brito Neves et al., op. cit.).

$\mathrm{O}$ evento $F_{3}$ parece ter constituído um episódio orogênico complexo ainda pouco conhecido. É possivel que um desenvolvimento similar ao modelo de Stephansson (op. cit.) tenha aqui ocorrido. Uma situação de instabilidade mecânico-gravitacional teria propiciado a subida de diápiros a partir de uma "camada granítica" subjacente.

Um ponto interessante a ser investigado é a caracterização das rochas básicas e suas relações com os granitos e a tectônica regional. É possível que os stocks e massas gabróides, como os de Laginha, Totoró, Janduis, Jardim de Angicos (RN) e outros, sejam correlatos às in- clusðes básicas de ocorrência generalizada nos granitos $G_{3}$. Neste caso, as intrusōes básicas na crosta poderiam ocasionar a instabilidade gravitacional referida, conforme propôs Stephansson (op. cit.) na Escandinávia. Se eles são diferentes, os xenólitos poderiam representar níveis básicos profundos da crosta "apanhados" pelos diápiros em sua subida. Isso é o que ocorre com os xenólitos de rochas granulíticas afloramentos das quais ainda são desconhecidos na região. Investigaçðes mineralógicas e geoquímicas novamente fazem-se necessárias.

A intrusão dos diápiros força lateralmente e aquece as encaixantes produzindo dobramentos e metamorfismo regional. Efeitos de contato seriam em geral obliterados; a cristalização seria dinâmica e/ou os minerais seriam em sua maior parte rotacionados/deformados a seguir. Isso explica a ausência de típicas auréolas na região, embora minerais "atectônicos" sejam localmente reconhecidos - andaluzita e cordierita em micaxistos, anfibólios em calcossilicáticas etc. A introdução de um grande volume de material granítico na crosta provoca tensões importantes e a cobertura é afetada por dobras com plano axial subvertical; sinformes revirados podem se formar nas proximidades de diápiros, como pode ser o caso na aba NE do Maciço de Acari (região de Brejuí-Barra Verde), tal qual sugerido por outros autores. Os experimentos de Ramberg $(1976,1970)$ são convincentes a esse respeito. $O$ diapirismo granítico atravessando a crosta constitui-se assim em um mecanismo adequado para explicar orogêneses ensiálicas (Shackleton, 1969), como parece ser o caso do evento Brasiliano nesta região do nordeste.

\section{BIBLIOGRAFIA}

ALMEIDA, F. F. M. de, LEONARDOS JR, , O. H. e VALENÇ, J. - 1967 - Review on granitic rocks of Northeast South America. IUGS/UNESCO Symp. Recife: $41 \mathrm{pp}$.

BRITO NEVES, B. B. de - 1975 - Regionalizaçâo tectônica do Precambriano Nordestino. Tese de doutoramento, Inst. Geoc., USP: 198 pp.

BRITO NEVES, B. B. de, VANDOROS, P. PESSOA, D. A. R. e CORDANI, U. G. - 1974 - Reavaliação dos dados geocronológicos do Pré-Cambriano do Nordeste brasileiro. Anais XXVIII Congr. Bras, Geol. 6: 261-271.

BRITO NEVES, B. B. de e PESSOA, R. J. R. - 1974 - Consideraçðes sobre as rochas graniticas do Nordeste oriental. Anais XXVIII Cong. Bras. Geol. 4: 143.157 .

BRITO NEVES, B. B. de, KAWASHITA, K. e PESSOA, D. A. R. - 1975 A posiçâo estratigráfica do Complexo Caicó. Atas VIII Simp. Geol. Nordeste, Fortaleza: 289-297.

CORDANI, U. G. - 1974 - Comentários sobre as determinaçðes geocro. nológicas disponiveis nas folhas Jaguaribe e Forraleza, in Dantas, J. R. A. Carta Geológica ao Milionésimo, Follsas Jaguaribe (SB-24) e Fortaleza (SA-24). Dep. Nac. Prod. Min.: 59-74

DANTAS, J. R. A. - 1974 - Carta Geológica do Brasil ao Milionésimo, Fothas Jaguaribe (SB-24) e Fortaleza (SA-24). Dep. Nac. Prod. Min.: 95 pp.

EBERT, H. - 1969 - Geologia do Alto Seridó. Sudene, Dep. Rec. Nat., Div. Geol., Sér. Geol. Reg. n: 11: 96 pp.

FERREIRA, J. A. M. e ALBUQUERQUE, J. P. T. - 1969 - Sinopse da geologia da Folha Serido. Sudene, Dep. Rec. Nat., Div. Geol, Sér, Geol. Reg. n: 18: $47 \mathrm{pp}$.

JARDIM DE SÁ, E. F. - 1978a - Revisăo preliminar sobre a "Faixa Dobrada do Serido" e eventuais correlatos no Nordeste. Rev. Ciência, Univ. Fed. Rio Grande do Norte, 1 (1): 77.83 .

JARDIM DE SÁ, E. F. - 19786 - Evoluçăo tectônica da regiđa do Seridó sintese preliminar, problemas e implicaçoes. Palestra prof. I Ciclo Est. Prospec. Scheelita Nordeste, Dep. Nac. Prod. Min., Currais Novos. Texto manuscr., $21 \mathrm{pp}$.

JARDIM DE SÁ, E. F., LEGRAND, J. M., MCREATH, I., SALIM, J., FIGUEIREDO, O. A., PETTA, R. A., SILVA, N. B. e GALINDO, A.C. -
1978 - Estratigrafia preliminar de rochas granitóides na região do Seridó (RN-PB). XXX Congr. Bras. Geol., Bol. n.. 1, Res. Com.: 310.

JARDIM DE SA, E. F. e SALIM, J. - 1980 - Reavaliação dos conceitos es tratigráficos na região do Seridó (RN-PB). Miner. Metal. 80 (421): 16-28.

LEGRAND, J. M. - 1977 - Nota preliminar sobre a estrutura diapirica do Maciço de Acari, e suas implicaçðes sobre a tectônica regional. VIII Simp. Geol. Nordeste, Bol. Esp., Res. Com.: 38.

McREATH, I. e JARDIM DE SÁ, E. F, - 1979 - Dataçð̃es geocronológicas em rochas policiclicas: interpretaço alternativa para os dados no Seridó (RN-PB). Atas IX Simp. Geol. Nordeste: 84-92.

MCREATH, 1, PERRIN, P. e estudantes das turmas 1976/1977 - 1979 - Corpos circulares e subcirculares na área divisória dos estados do Rio Grande do Norte e Paraiba. Atas IX Simp. Geol. Nordeste: 52-53.

MELlo, A. A. de - 1972 - O granitóide de Acari. Rev. Assoc. Geol. Pernambuco II (5): $43-59$.

RAMBERG, H. - 1967 - Gravity deformation and the Earth's crust as studied by centrifuged models. Academic Press, Londres e Nova York: 214 pp.

RAMBERG, $\mathrm{H}-1970-$ Model studies in relation to intrusion of plutonic bo dies, in Mechanism of Igneous Intrusion, Eds. G. Newall e N. Rast, Gallery Press, Liverpool: 261-286.

SANTOS, E. J. dos - 1973 - Província Scheelitifera do Nordeste. XXVII Congr. Bras. Geol., Bol. Esp. n? 8: 31-46.

SANTOS, E. J. dos e MELO, C. B. M. - 1978 - Diversidade do plutonismo granítico Brasiliano do Nordeste. Anais $X X X$ Congr. Bras, Geol. 6: 2624-2634.

SHACKLETON, R. M. - 1969 - Displacement within continents, in Time and Place in Orogeny, Eds. P. E. Kent, G. E. Satterhwait e A. M. Spencer, Geol. Soc. Lond. Spec. Publ. 3: 1-7.

STEPHANSSON, O. - 1975 - Polydiapirism of granitic rocks in the Svecofennian of Central Sweden. Precambrian Res. 2: 189-214. 